\title{
Feasibility of balloon endoscope-assisted endoscopic retrograde cholangiopancreatography for the elderly
}

\section{(ㄷ)(1) $\odot$}

\begin{abstract}
Authors
\end{abstract}
Ryunosuke Hakuta*,, , Hirofumi Kogure*, , Yousuke Nakai ${ }^{1,2}$, Tsuyoshi Hamada', Tatsuya Sato', Yukari Suzuki ${ }^{1}$, Akiyuki Inokuma' ${ }^{1}$, Sachiko Kanai ${ }^{1}$, Tomoka Nakamura' ${ }^{1}$, Kensaku Noguchi ${ }^{1}$, Kazunaga Ishigaki ${ }^{1}$, Kei Saito' ${ }^{1}$, Tomotaka Saito', Naminatsu Takahara', Suguru Mizuno' ${ }^{1}$, Atsuo Yamada', Minoru Tada', Kazuhiko Koike ${ }^{1}$

with a high technical success rate, but adverse events (AEs) are not uncommon. Compared to non-elderly patients, elderly patients may be at higher risk of AEs due to underlying comorbidities. The current study aimed to evaluate the feasibility of balloon endoscope-assisted ERCP (BE-

\author{
submitted 29.2.2020 \\ accepted after revision $\quad 2.7 .2020$ \\ Bibliography \\ DOI https://doi.org/10.1055/a-1216-1363 | \\ Endoscopy International Open 2020; 08: E1202-E1211 \\ (c) Georg Thieme Verlag KG Stuttgart · New York \\ elSSN 2196-9736 \\ Corresponding author \\ Yousuke Nakai, MD, PhD, Department of Endoscopy and \\ Endoscopic Surgery, Graduate School of Medicine, The \\ University of Tokyo, 7-3-1 Hongo, Bunkyo-ku, Tokyo 113- \\ 8655, Japan \\ Fax: +81-3-5800-9801 \\ ynakai-tky@umin.ac.jp
}

\section{ABSTRACT}

Background and study aims Endoscopic retrograde cholangiopancreatography (ERCP) for patients with surgically altered anatomy is challenging. Recently, balloon endoscopy has been shown to facilitate ERCP for this population ERCP) for the elderly.

Patients and methods We retrospectively identified patients who underwent BE-ERCP between January 2010 and September 2019. For patients who underwent multiple procedures during the study period, the first session was analyzed. Early AEs associated with BE-ERCP were compared between elderly ( $\geq 75$ years) and non-elderly patients.

Results A total of 1,363 BE-ERCP procedures were performed, and 568 patients (211 elderly and 357 non-elderly) were included for the analyses. Technical success rates were high in both the elderly and non-elderly groups (80\% vs. $80 \%$, respectively). The rates of early AEs were similar between the groups ( $12 \%$ vs. $9.0 \%$ in the elderly and nonelderly group, respectively; $P=0.31$ ). The mltivariable-adjusted odds ratio for early AEs comparing elderly to non-elderly patients was 1.36 (95\% confidence interval, $0.74-$ $2.51 ; P=0.32$ ). Specifically, we did not observe betweengroup differences in rates of gastrointestinal perforation ( $2.4 \%$ vs. $2.8 \%$ in elderly and non-elderly groups, respectively; $P=0.99)$ and aspiration pneumonia ( $1.9 \%$ vs. $0.6 \%$, $P=0.20)$.

Conclusions BE-ERCP is a feasible procedure for elderly individuals with surgically altered anatomy.

\section{Introduction}

Endoscopic retrograde cholangiopancreatography (ERCP) is a widely performed diagnostic and therapeutic procedure for a variety of pancreatobiliary diseases. However, ERCP for patients with surgically altered anatomy is challenging because intubation of a side-viewing duodenoscope is technically difficult and sometimes risky, especially in cases with Roux-en-Y reconstruction [1]. Recently, a balloon endoscope is an emergent treat-

\footnotetext{
* These authors contributed equally.
}

ment modality that has dramatically increased the technical success rate of ERCP for that population [2-8]. Studies suggest the safety of balloon endoscope-assisted ERCP (BE-ERCP) [912 ]. but attention should be paid to potential procedure-related adverse events (AEs) including gastrointestinal perforation, aspiration pneumonia, and pancreatitis [13].

With the aging population, there is an increasing opportunity to perform ERCP for elderly patients. Due to serious comorbidities such as cardiovascular or cerebrovascular diseases, elderly patients receiving therapeutic ERCP may be associated with higher morbidity and mortality compared to non-elderly 
patients $[14,15]$. Elderly people may be predisposed to risk of aspiration pneumonia based on impaired pharyngoglottal reflex and reflexive pharyngeal swallow $[16,17]$. Furthermore, clinical evidence suggests an increased risk of gastrointestinal perforation in colonoscopy in the elderly $[18,19]$. Although previous retrospective studies showed the safety of standard ERCP or enteroscopy for elderly patients $[20,21]$, the safely and feasibility of BE-ERCP have not been fully investigated.

To examine the feasibility of BE-ERCP for the elderly ( $\geq 75$ years), we conducted a large observational study at a single referral center in Japan.

\section{Patients and methods}

\section{Study design and population}

The current study was a single-center retrospective cohort study to evaluate the safety of BE-ERCP for the elderly. We identified consecutive patients with surgically altered anatomy who underwent BE-ERCP through our prospectively-maintained ERCP database. For patients who underwent multiple BE-ERCP sessions during the study period, we analyzed the first session for each patient. We excluded patients with Billroth-I reconstruction. Clinical outcomes were compared between the elderly ( $\geq 75$ years old) and non-elderly patients ( $<75$ years old). The primary outcome was incidence of early AEs associated with BE-ERCP. The secondary outcomes included the technical success rate of BE-ERCP and specific AEs (e. g., aspiration pneumonia, gastrointestinal perforation, and pancreatitis).

This study was conducted according to the guidelines in the Helsinki Declaration and was approved by the ethics committee of the University of Tokyo (Tokyo, Japan). Written informed consent for the procedure was obtained from each patient before the procedure. Consent for the use of data was obtained on the opt-out basis.

\section{Endoscopic procedures}

Prior to the procedure, we assessed physical status of patients. BE-ERCP was considered as contraindicated when patients were highly disabled (with Eastern Cooperative Oncology Group Performance Status [PS] $>3$ or American Society of Anesthesiologists Physical Status Classification score [ASA-PS] >4), had unstable vital signs (e.g., septic shock, or hypoxia requiring highvolume oxygen), or with dysphagia. For patients who were likely to have dysphagia, otolaryngologists evaluated swallowing function before the procedure. Percutaneous transhepatic biliary drainage (PTBD) was performed for patients who could not undergo BE-ERCP.

ERCP was performed using a short-type double-balloon endoscope (EC-450BI5/El-530B with a 2.8-mm-wide working channel or El-580BT with a 3.2-mm-wide working channel; Fujifilm, Tokyo, Japan) with $\mathrm{CO}_{2}$ insufflation. During the study period, EC-450BI5 or El-530B was initially used and El-580BT was used since July 2015 [22]. BE-ERCP was performed under moderate sedation with intravenous injection of diazepam or midazolam and pethidine hydrochloride during the procedure, and continuous intravenous administration of dexmedetomidine hydrochloride. The details of BE-ERCP procedures in our institution were reported previously $[23,24]$.

Biliary or pancreatic cannulation was attempted via wireguided or contrast-assisted method using a cannula (MTW Endoskopie, Wesel, Germany) or sphincterotome (Truetome, Boston Scientific Japan, Tokyo, Japan) and a 0.025-inch guidewire (VisiGlide2, Olympus, Tokyo, Japan; Endoselector, Boston Scientific Japan). Sphincteroplasty (endoscopic papillary balloon dilation [EPBD] or endoscopic papillary large balloon dilation [EPLBD] without sphincterotomy) using a balloon catheter (Hurricane RX or CRE wire-guided balloon dilator, Boston Scientific Japan; ZARA or GIGA2, Century Medical, Tokyo, Japan) was performed before stone extraction for patients with intact papilla, as previously reported [25-27]. Basket (TetraCatch $V$ and FlowerBasket V, Olympus) and/or balloon catheters (Multi-3V Extraction Balloon, Olympus) were used for the removal of bile duct stones [28]. Endoscopic mechanical lithotripsy (LithoCrushV, Olympus) was performed if needed. Balloon dilation (Hurricane RX, Boston Scientific Japan; REN, Kaneka Medix Corp., Osaka, Japan) was performed for benign strictures of the bile duct, pancreatic duct, and anastomotic strictures. A plastic stent or a metal stent was placed for cases of benign stricture or malignant biliary obstruction [29].

All patients were admitted to our hospital the day before BE$E R C P$, and were discharged in 2 days after the procedure unless they developed AEs.

\section{Definitions of outcome variables}

AEs and their severities were defined according to the lexicon guidelines proposed by American Society of Gastrointestinal Endoscopy [30]. AEs were defined as early when they developed within 14 days of the index ERCP. Severity of early AEs was graded as follows: mild, requiring an unplanned prolongation of hospital stay $\leq 3$ days; moderate, requiring an unplanned prolongation of hospital stay for 4 to 10 days, endoscopy, interventional radiology, or admission to the intensive care unit for one night; and severe, requiring an unplanned prolongation of hospital stay for $>10$ days, admission to the intensive care unit for $>$ 1 night, or surgical intervention. Technical success was defined as successful biliary or pancreatic cannulation, and subsequent stone removal, balloon dilation, or stent placement, if needed [9].

\section{Statistical analysis}

Categorical variables were compared using the chi-square test or Fisher's exact test, as appropriate. Continuous variables were compared using the Wilcoxon rank-sum test.

Univariable and multi-variable logistic regression models were used to estimate odds ratios (OR) and corresponding $95 \%$ confidence interval $(\mathrm{Cl})$ of early adverse events. The multivariable model included variables with $P<0.10$ in a univariable model in addition to age ( $\geq 75$ vs. $<75$ years old).

For all analyses, a two-sided $P<0.05$ was used to denote statistical significance. All statistical analyses were performed using the EZR software (Saitama Medical Center, Jichi Medical University, Saitama, Japan) [31], which is a graphical user inter- 
568 patients underwent 1,363 BE-ERCP procedures between Jan 2010 and Sep 2019

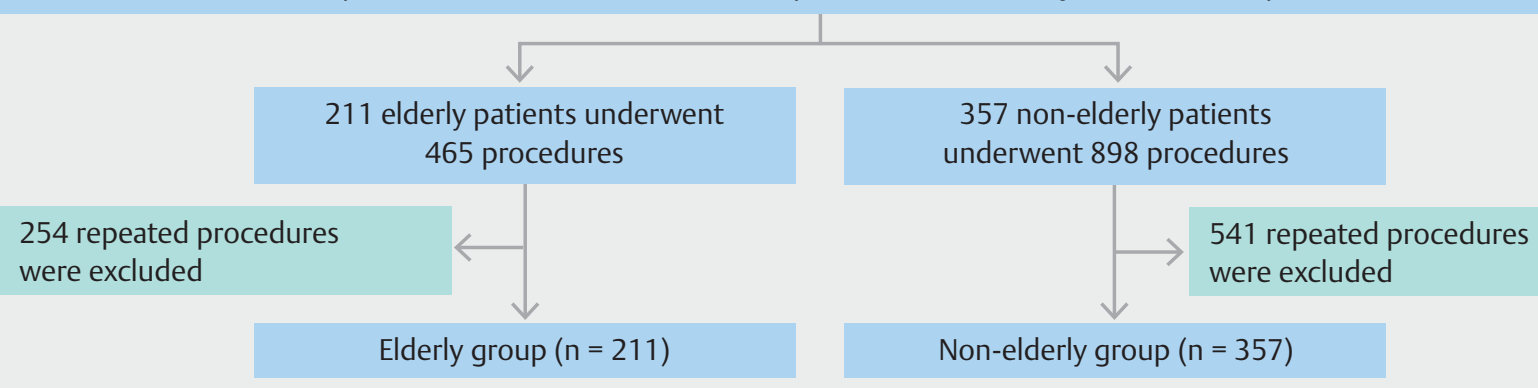

- Fig. 1 Selection of elderly (aged $\geq 75$ years old) and non-elderly patients (aged $<75$ years old) who underwent balloon endoscope-assisted endoscopic retrograde cholangiopancreatography. BE-ERCP, balloon endoscope-assisted endoscopic retrograde cholangiopancreatography.

face for the R software (The R Foundation for Statistical Computing, Vienna, Austria, version 3.4.1).

\section{Results}

A total of 1,363 BE-ERCP procedures were performed for 568 patients between January 2010 and September 2019. After excluding repeated BE-ERCP sessions, 211 elderly and 357 non-elderly patients were included for the analyses ( $\triangleright$ Fig. 1).

- Table 1 shows baseline characteristics of the study population. As expected, elderly patients were more likely to have higher scores of PS and ASA-PS and take antithrombotic agents regularly as compared with non-elderly patients. BE-ERCP was more likely indicated for bile duct stones in elderly patients than in non-elderly patients. The rates of other indications were comparable between the groups. Overall, the major type of surgery and gastrointestinal reconstruction was gastrectomy with Roux-en-Y reconstruction.

$\checkmark$ Table 2 shows the details of BE-ERCP procedures ( $\triangleright$ Fig. 2 ). The technical success rates were both $80 \%$ in the elderly and non-elderly groups $(P=0.91)$. Median procedure time of $\mathrm{BE}-$ ERCP was 69 minutes in the elderly group and 65 minutes in the non-elderly group $(P=0.49)$. Reasons for 114 technical failures were failed scope insertion in 53 and failed biliary or pancreatic duct cannulation in 61 (39 with intact papilla, and 22 with pancreatico- or hepatico-jejunostomy). Those patients were successfully managed by PTBD $(n=52)$, interventional endoscopic ultrasonography $(n=34)$, repeated BE-ERCP $(n=1)$, conservative treatment $(n=23)$, or surgery $(n=4)$. Compared with non-elderly patients, elderly patients were more likely to undergo EPBD and bile duct stone removal during BE-ERCP. The median number of BE-ERCP sessions during the study period was two in the elderly group and one in the non-elderly group $(P=0.76)$.

Incidences of early AEs were similar between the elderly and non-elderly groups ( $12 \%$ vs. $9.0 \%, P=0.31$; Table 3 ). The multivariable-adjusted OR for early AEs comparing elderly to nonelderly patients was 1.36 (95\% Cl 0.74-2.51, $P=0.32$; > Table4 and Supplementary Table 1). Sensitivity analysis excluding patients with failed scope insertion did not alter our findings (multivariable-adjusted OR 1.25, 95\% Cl 0.67-2.32, $P=0.49$ ). Furthermore, analyses including total BE-ERCP sessions also showed similar incidences of early adverse events between the groups $(9.5 \%$ vs. $7.2 \%$ in the elderly and non-elderly group, respectively; $P=0.17$; Supplementary Table 2 ). Gastrointestinal perforation was observed in $2.4 \%$ of the elderly patients and $2.8 \%$ of the non-elderly patients $(P=0.99)$. Among the three who developed severe perforation, one elderly patient with Billroth-II reconstruction underwent emergent surgery and the other two (one elderly and one non-elderly patient) were hospitalized for $>10$ days but were managed conservatively without interventions. Furthermore, the rates of gastrointestinal perforation were not different by the type of gastrointestinal reconstruction (2.9\% vs. $2.1 \%$ in patients with Roux-en$Y$ reconstruction or Billroth-II, respectively; $P=0.86)$. Aspiration pneumonia was observed in four $(1.9 \%)$ elderly patients and two $(0.6 \%)$ non-elderly patients $(P=0.20)$. median procedure time of these six patients was 119 minutes. The multivariable logistic regression model suggested lengthy procedure (>90 minutes) as a risk factor of early AEs (multivariable-adjusted OR 1.98, 95\% Cl 1.08-3.60; $P=0.03$ ). Rates of other early AEs including post-ERCP pancreatitis and bleeding were similar between the groups. Any fatal AE was not observed in our study cohort.

\section{Discussion}

The current study was a large-scale retrospective study including 568 patients to evaluate the feasibility of BE-ERCP for the elderly. The early AEs associated with BE-ERCP were observed in $12 \%$ of elderly patients compared with $9.0 \%$ of non-elderly patients. Furthermore, incidences of gastrointestinal perforation and aspiration pneumonia were similar between the elderly and non-elderly groups, and the high technical success rate (80\%) was achieved in both groups.

Despite higher likelihood of regular use of antithrombotic agents and impaired physical activity in elderly patients, our study suggested the feasibility of BE-ERCP for this patient population. Incidence of early AEs related to BE-ERCP was reported to be $1.6 \%$ to $12.5 \%[6,9,13,23,32,33]$. In a recent large-scale, 
- Table 1 Baseline characteristics of elderly and non-elderly patients who underwent balloon endoscope-assisted endoscopic retrograde cholangiopancreatography.

\begin{tabular}{|c|c|c|c|}
\hline Characteristic $^{1}$ & Elderly $(n=211)$ & Non-elderly $(n=357)$ & $P$ value \\
\hline Gender & & & 0.007 \\
\hline - Male & $149(71 \%)$ & $211(59 \%)$ & \\
\hline - Female & $62(29 \%)$ & $146(41 \%)$ & \\
\hline $\begin{array}{l}\text { Performance status }{ }^{2} \text {, } \\
0 / 1 / 2 / \geq 3\end{array}$ & $\begin{array}{l}72 / 97 / 26 / 16 \\
(34 \% / 46 \% / 12 \% / 7.6 \%)\end{array}$ & $\begin{array}{l}177 / 151 / 25 / 4 \\
(50 \% / 42 \% / 7.0 \% / 1.1 \%)\end{array}$ & $<0.001$ \\
\hline $\begin{array}{l}\text { ASA-PS score }{ }^{3} \text {, } \\
1 / 2 / 3 / 4\end{array}$ & $\begin{array}{l}35 / 123 / 49 / 4 \\
(17 \% / 58 \% / 23 \% / 1.9 \%)\end{array}$ & $\begin{array}{l}124 / 151 / 77 / 5 \\
(35 \% / 42 \% / 22 \% / 1.4 \%)\end{array}$ & $<0.001$ \\
\hline \multicolumn{4}{|l|}{ Indication for ERCP } \\
\hline - Bile duct stone & $112(53 \%)$ & $124(35 \%)$ & $<0.001$ \\
\hline - Benign biliary stricture & $50(24 \%)$ & $109(31 \%)$ & 0.08 \\
\hline - Malignant biliary obstruction & $30(14 \%)$ & $59(17 \%)$ & 0.55 \\
\hline - Cholangitis & $15(7.1 \%)$ & $29(8.1 \%)$ & 0.75 \\
\hline - Pancreatic intervention & $4(1.9 \%)$ & $36(10 \%)$ & $<0.001$ \\
\hline \multicolumn{4}{|l|}{ Type of surgery/GI reconstruction } \\
\hline - Gastrectomy/Roux-en-Y & $95(45 \%)$ & $83(23 \%)$ & $<0.001$ \\
\hline - Gastrectomy/Billroth-II & $18(8.5 \%)$ & $17(4.8 \%)$ & 0.10 \\
\hline - Pancreaticoduodenectomy/Roux-en-Y & $25(12 \%)$ & $54(15 \%)$ & 0.32 \\
\hline - Pancreaticoduodenectomy/Billroth-II & $32(15 \%)$ & $65(18 \%)$ & 0.42 \\
\hline - Extrahepatic bile duct resection/Roux-en-Y & $20(9.5 \%)$ & $84(24 \%)$ & $<0.001$ \\
\hline - Others & $21(10 \%)$ & $54(15 \%)$ & 0.10 \\
\hline Antithrombotic agents & $31(15 \%)$ & $23(6.4 \%)$ & 0.002 \\
\hline - Antiplatelet & $25(12 \%)$ & $16(4.5 \%)$ & 0.002 \\
\hline - Anticoagulant & $6(2.8 \%)$ & $7(2.0 \%)$ & 0.57 \\
\hline Type of scope & & & 0.34 \\
\hline - $\mathrm{EC}-450 \mathrm{BI} 5$ or El-530B (2010-2015) & $88(42 \%)$ & $164(46 \%)$ & \\
\hline - EI-580BT (2015-2019) & $123(58 \%)$ & $193(54 \%)$ & \\
\hline \multicolumn{4}{|c|}{$\begin{array}{l}\text { ASA-PS, American Society of Anesthesiologists Physical Status Classification; ERCP, endoscopic retrograde cholangiopancreatography; GI, gastrointestinal. } \\
1 \text { Data are expressed as number (percentage) of patients within a given group. } \\
2 \text { Performance status is defined as follows: } 0 \text {, fully active, able to carry on all pre-disease performance without restriction; } 1 \text {, restricted in physically strenuous activity } \\
\text { but ambulatory and able to carry out work of a light or sedentary nature; } 2 \text {, ambulatory and capable of all self-care but unable to carry out any work activities; } 3 \text {, } \\
\text { capable of only limited self-care; } 4 \text {, completely disabled; } 5 \text {, dead. } \\
{ }^{3} \text { ASA-PS score is defined as follows: } 1 \text {, a normal healthy patient; } 2 \text {, a patient with a mild systemic disease; } 3 \text {, a patient with a severe systemic disease; } 4 \text {, a patient with } \\
\text { a life-threatening systemic disease; } 5 \text {, a moribund patient who is not expected to survive without the operation; and } 6 \text {, a declared brain-dead patient whose organs } \\
\text { are removed for donor purposes. }\end{array}$} \\
\hline
\end{tabular}

multicenter prospective, study including 311 patients receiving BE-ERCP, the rate of early AEs was $10.6 \%$ [9]. Of note, the current study showed comparable incidences of early AEs to those reported in the previous studies. Furthermore, no fatal AE was observed in the elderly group in our study cohort. In addition, intended procedures were successfully performed for the majority of our elderly patients. Taken together, BE-ERCP may become a first-line non-surgical treatment strategy for elderly patients with surgically altered anatomy.
Aspiration pneumonia is a commonly encountered disease among geriatric patients with dysphagia [34]. Prevalence of oropharyngeal dysphagia was reported to be $13 \%$ of individuals aged over 65 years, and the risk can be further enhanced if they concomitantly have neurological comorbidity, frailty, or advanced age [35]. The use of sedatives during therapeutic endoscopy potentially increases the risk of aspiration pneumonia particularly in the elderly. [17] In the setting of BE-ERCP, the procedure time tends to be longer compared to standard ERCP, potentially increasing the risk of this AE. Attention should be 
- Table 2 Endoscopic procedures for elderly and non-elderly patients.

\begin{tabular}{|c|c|c|c|}
\hline Procedure $^{1}$ & Elderly $(n=211)$ & Non-elderly $(n=357)$ & $P$ value \\
\hline Technical success & $168(80 \%)$ & $286(80 \%)$ & 0.91 \\
\hline Total procedure time, minutes & $69(46-95)$ & 65 (42-95) & 0.49 \\
\hline Successful scope insertion & $196(93 \%)$ & $319(89 \%)$ & 0.18 \\
\hline Total number of ERCP session during the study period & $2(1-3)$ & $1(1-3)$ & 0.76 \\
\hline \multicolumn{4}{|l|}{ Sphincteroplasty } \\
\hline - EPBD & $44(21 \%)$ & $35(9.8 \%)$ & $<0.001$ \\
\hline - EPLBD & $24(11 \%)$ & $23(6.4 \%)$ & 0.06 \\
\hline Bile duct stone removal & $106(50 \%)$ & $147(41 \%)$ & 0.04 \\
\hline Lithotripsy & $19(9.0 \%)$ & $46(13 \%)$ & 0.17 \\
\hline \multicolumn{4}{|l|}{ Balloon dilation } \\
\hline - Biliary stricture & $38(18 \%)$ & $89(25 \%)$ & 0.06 \\
\hline - Pancreatic stricture & $1(0.5 \%)$ & $17(4.8 \%)$ & 0.005 \\
\hline \multicolumn{4}{|l|}{ Stent placement } \\
\hline - Biliary & $82(39 \%)$ & $113(32 \%)$ & 0.08 \\
\hline - Pancreatic & 0 & $8(2.2 \%)$ & 0.03 \\
\hline
\end{tabular}
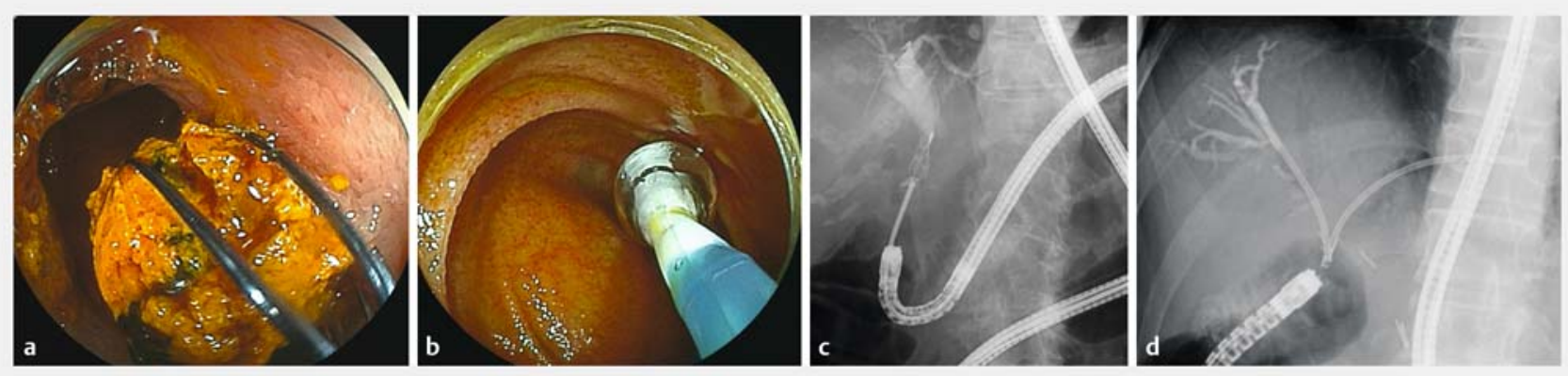

- Fig. 2 Endoscopic and fluoroscopic images of balloon endoscope-assisted endoscopic retrograde cholangiopancreatography. a Endoscopic image of bile duct stone removal using a basket catheter. b Balloon dilation for benign biliary stricture at the anastomosis of hepaticojejunostomy. c Fluoroscopic image of bile duct stone removal using endoscopic mechanical lithotripsy. $\mathbf{d}$ Biliary stent placement for hepaticojejunostomy anastomotic stricture.

paid not only during endoscopy but also after the post-procedural observation period as the sedative effect may be prolonged due to low drug metabolism in the elderly [36]. Median procedure time in four (1.9\%) elderly patients who developed aspiration pneumonia was as long as 110 minutes.

Furthermore, the multivariable model suggested the association between long procedure time (>90 minutes) and increased risk of early AEs ( $\triangleright$ Supplementary Table 1 ). It seems better to avoid lengthy procedures for the elderly to prevent aspiration pneumonia, but a further investigation is required to determine the optimal procedure time for elderly patients receiving BE-ERCP.
Gastrointestinal perforation is another potentially fatal $\mathrm{AE}$ associated with BE-ERCP. In the current study, this AE was observed in 15 patients ( $3 \%$ ) including one patient who needed emergent surgery. Considering similar incidences of gastrointestinal perforation reported in the literature $[3,9,37]$, this serious $A E$ is not uncommon in BE-ERCP. Furthermore, advancing age was reported as a risk factor for gastrointestinal perforation after colonoscopy $[18,19]$. Perforation in the elderly was supposedly caused by reduction in tissue elasticity or muscle function, not by endoscopic polypectomy or biopsy [19,35]. Another potential risk factor for gastrointestinal perforation is a type of gastrointestinal reconstruction. Although the Roux- 
- Table 3 Incidences and severities of early adverse events associated with balloon endoscope-assisted endoscopic retrograde cholangiopancreatography in elderly and non-elderly patients.

\begin{tabular}{|c|c|c|c|}
\hline Early adverse events ${ }^{1}$ & Elderly $(n=211)$ & Non-elderly $(n=357)$ & $P$ value \\
\hline Total & $25(12 \%)$ & $32(9.0 \%)$ & 0.31 \\
\hline Gl perforation² & $5(2.4 \%)$ & $10(2.8 \%)$ & 0.99 \\
\hline - Severe & $2(0.9 \%)$ & $1(0.3 \%)$ & 0.56 \\
\hline Aspiration pneumonia & $4(1.9 \%)$ & $2(0.6 \%)$ & 0.20 \\
\hline - Severe & 0 & 0 & NA \\
\hline Pancreatitis ${ }^{23}$ & $7(3.3 \%)$ & $9(2.5 \%)$ & 0.61 \\
\hline - Severe & $2(0.9 \%)$ & 0 & 0.14 \\
\hline Bleeding & $1(0.5 \%)$ & 0 & 0.37 \\
\hline - Severe & 0 & 0 & NA \\
\hline Cholangitis & $7(3.3 \%)$ & $11(3.1 \%)$ & 0.99 \\
\hline Cholecystitis & $2(0.9 \%)$ & 0 & 0.14 \\
\hline Bile duct injury & $1(0.5 \%)$ & 0 & 0.37 \\
\hline Hoarseness & $1(0.5 \%)$ & 0 & 0.37 \\
\hline
\end{tabular}

- Table 4 Logistic regression analyses to assess the association of age with incidence of early adverse events associated with balloon endoscopeassisted endoscopic retrograde cholangiopancreatography.

\begin{tabular}{|c|c|c|c|c|c|c|}
\hline \multirow[b]{2}{*}{ Subgroup } & \multirow[b]{2}{*}{ Total, n } & \multirow[b]{2}{*}{ eAE, n (\%) } & \multicolumn{4}{|l|}{ OR $(95 \% \mathrm{CI})$} \\
\hline & & & Univariable & $P$ value & Multivariable $^{1}$ & $P$ value \\
\hline \multicolumn{7}{|l|}{ Age } \\
\hline . <75 years & 357 & $32(9.0 \%)$ & 1 (referent) & & 1 (referent) & \\
\hline - $\geq 75$ years & 211 & $25(12 \%)$ & $1.37(0.79-2.37)$ & 0.27 & $1.36(0.74-2.51)$ & 0.32 \\
\hline \multicolumn{7}{|c|}{$\begin{array}{l}\mathrm{Cl} \text {, confidence interval; eAE, early adverse event; OR, odds ratio. } \\
1{ }^{1} \text { To select variables for the final multivariable model, a univariable logistic regression model was examined for each of the following variables: gender (female or } \\
\text { male), Performance Status ( }<2 \text { or } \geq 2 \text { ), American Society of Anesthesiologists Physical Status Classification }(\leq 2 \text { or }>2 \text { ), indication for endoscopic retrograde cho- } \\
\text { langiopancreatography (bile duct stone, benign biliary stricture, malignant biliary obstruction, cholangitis, or pancreatic intervention), type of surgery (choledo- } \\
\text { chojejunostomy, gastrectomy, pancreaticoduodenectomy, or other), gastrointestinal reconstruction (Billroth-II, or Roux-en-Y, or other), use of antithrombotic } \\
\text { agents (yes or no), type of scope (EC-450BI5/El-530B or EI-580BT), successful scope insertion (yes or no), bile duct stone removal (yes or no), sphincteroplasty (no, } \\
\text { endoscopic papillary balloon dilation, or endoscopic papillary large balloon dilation), balloon dilation for biliary or pancreatic stricture (yes or no), biliary stent } \\
\text { placement (yes or no), and procedure time ( } \leq 90 \text { minutes or }>90 \text { minutes). In addition to age ( } \geq 75 \text { years vs. }<75 \text { years), variables with } P<0.10 \text { in univariable analyses } \\
\text { were entered into the multivariable model. The final model was described in Supplementary Table } 1 \text {. }\end{array}$} \\
\hline
\end{tabular}

en-Y reconstruction was associated with a procedural failure [38], Billroth-II reconstruction was a possible risk factor of obvious perforation during BE-ERCP [9]. Contrary to microperforation which could be often managed conservatively, we believe that obvious perforation is the most dreaded $A E$ in $B E-$ $E R C P$, often necessitating surgical repair. Thus, an indication of BE-ERCP for elderly patients with Billroth-II reconstruction should be considered prudently.

A double balloon endoscope was used in our study, but a single balloon endoscope is another option for ERCP in patients with surgically altered anatomy. Only one retrospective study
[39] compared long-type, not short-type, single and double balloon endoscopes for ERCP, and demonstrated similar outcomes between two scopes. Recently, two studies [38, 40] reported clinical outcomes of a short-type single balloon endoscope for ERCP with technical success rates of $81.8 \%$ and $85.9 \%$ and $\mathrm{AE}$ rates of $5.9 \%$ and $8.4 \%$, respectively, which is comparable to our study results. Although there were no studies comparing two short-type balloon endoscopes, it is reasonable to say the type of balloon endoscopes can be selected depending on the local expertise. 
The large sample size is a major strength of our study. We performed 1,363 BE-ERCP procedures during the study period and included 568 patients for the analysis. Our study had the largest sample size among previous clinical studies and could give a robust estimation for the safety of BE-ERCP. Furthermore, a prospectively-maintained endoscopy database allowed us to adjust potential confounding variables which could be associated with early AEs.

Our study had limitations. First, the retrospective and singlecenter design was a limitation; therefore, our findings should be validated in prospective multicenter cohorts. Second, an indication of BE-ERCP in each patient was decided by attending physicians. As we avoided BE-ERCP for patients with poor physical status or highly suspected dysphagia, our study results could not validate the safety of BE-ERCP for these patients. Finally, we consecutively performed BE-ERCP for patients with Billroth-II reconstruction. However, the effectiveness and safety of side- or forward-viewing endoscope was also reported for ERCP in this population [41]. Considering that Billroth-II is the potential risk factor of obvious perforation during BE-ERCP, further comparative study should be conducted in this setting.

\section{Conclusion}

In summary, BE-ERCP is a feasible procedure for elderly individuals with surgically altered anatomy. However, indication of BEERCP for elderly patients with Billroth-II reconstruction should be selected with a caution because of the potential risk of gastrointestinal perforation. A further validation study is warranted before BE-ERCP can become the gold standard procedure for management of pancreatobiliary diseases among elderly patients with a history of gastrointestinal reconstruction.

\section{Competing interests}

The authors declare that they have no conflict of interest.

\section{References}

[1] Nakai Y, Kogure H, Yamada A et al. Endoscopic management of bile duct stones in patients with surgically altered anatomy. Dig Endosc 2018; 30: 67-74

[2] Aabakken L, Bretthauer M, Line PD. Double-balloon enteroscopy for endoscopic retrograde cholangiography in patients with a Roux-en-Y anastomosis. Endoscopy 2007; 39: 1068-1071

[3] Shimatani M, Matsushita M, Takaoka M et al. Effective "short" doubleballoon enteroscope for diagnostic and therapeutic ERCP in patients with altered gastrointestinal anatomy: a large case series. Endoscopy 2009; 41: 849-854

[4] Maaser C, Lenze F, Bokemeyer M et al. Double balloon enteroscopy: a useful tool for diagnostic and therapeutic procedures in the pancreaticobiliary system. Am J Gastroenterol 2008; 103: 894-900

[5] Katanuma A, Isayama H. Current status of endoscopic retrograde cholangiopancreatography in patients with surgically altered anatomy in Japan: questionnaire survey and important discussion points at Endoscopic Forum Japan 2013. Dig Endosc 2014; 26: 109-115
[6] Itokawa F, Itoi T, Ishii K et al. Single- and double-balloon enteroscopyassisted endoscopic retrograde cholangiopancreatography in patients with Roux-en-Y plus hepaticojejunostomy anastomosis and Whipple resection. Dig Endosc 2014; 26: 136-143

[7] Neumann H, Fry LC, Meyer F et al. Endoscopic retrograde cholangiopancreatography using the single balloon enteroscope technique in patients with Roux-en-Y anastomosis. Digestion 2009; 80: 52-57

[8] Skinner M, Gutierrez JP, Wilcox CM et al. Overtube-assisted placement of a metal stent into the bile duct of a patient with surgically altered upper-gastrointestinal anatomy during double-balloon enteroscopyassisted ERCP. Endoscopy 2013; 45: E418-419

[9] Shimatani M, Hatanaka H, Kogure $\mathrm{H}$ et al. Diagnostic and therapeutic endoscopic retrograde cholangiography using a short-type doubleballoon endoscope in patients with altered gastrointestinal anatomy: a multicenter prospective study in Japan. Am J Gastroenterol 2016; 111: 1750-1758

[10] Obana T, Fujita N, Ito K et al. Therapeutic endoscopic retrograde cholangiography using a single-balloon enteroscope in patients with Roux-en-Y anastomosis. Dig Endosc 2013; 25: 601-607

[11] Kato H, Tsutsumi K, Harada R et al. Short double-balloon enteroscopy is feasible and effective for endoscopic retrograde cholangiopancreatography in patients with surgically altered gastrointestinal anatomy. Dig Endosc 2014; 26: 130-135

[12] Monkemuller K, Fry LC, Bellutti M et al. ERCP with the double balloon enteroscope in patients with Roux-en-Y anastomosis. Surg Endosc 2009; 23: 1961-1967

[13] Skinner M, Popa D, Neumann H et al. ERCP with the overtube-assisted enteroscopy technique: a systematic review. Endoscopy 2014; 46: 560-572

[14] Chandrasekhara V, Early DS et al. ASGE Standards of Practice Committee. Modifications in endoscopic practice for the elderly. Gastrointest Endosc 2013; 78: 1-7

[15] Warren J, Klabunde C, Mariotto A et al. Adverse events after outpatient colonoscopy in the Midicare population. Ann Intern Med 2009; 150: 849-857

[16] Kiyohara H, Umezaki T, Sawatsubashi M et al. Evaluation of bolitional and reflexive swallowing in elderly patients. Ann Otol Rhinol Laryngol 2012; 121: 174-178

[17] Shaker R, Ren J, Bardan E et al. Pharyngoglottal closure reflex: characterization in healthy young, elderly and dysphagic patients with predeglutitive aspiration. Gerontology 2003; 49: 12-20

[18] Day LW, Kwon A, Inadomi JM et al. Adverse events in older patients undergoing colonoscopy: a systematic review and meta-analysis. Gastrointest Endosc 2011; 74: 885-896

[19] Arora G, Mannalithara A, Singh G et al. Risk of perforation from a colonoscopy in adults: a large population-based study. Gastrointest Endosc 2009; 69: 654-664

[20] Hegde SR, Iffrig K, Li T et al. Double-balloon enteroscopy in the elderly: safety, findings, and diagnostic and therapeutic success. Gastrointest Endosc 2010; 71: 983-989

[21] Ito Y, Tsujino T, Togawa O et al. Endoscopic papillary balloon dilation for the management of bile duct stones in patients 85 years of age and older. Gastrointest Endosc 2008; 68: 477-482

[22] Yamada A, Kogure H, Nakai Y et al. Performance of a new short-type double-balloon endoscope with advanced force transmission and adaptive bending for pancreaticobiliary intervention in patients with surgically altered anatomy: A propensity-matched analysis. Dig Endosc 2019; 31: 86-93

[23] Tsujino T, Yamada A, Isayama $\mathrm{H}$ et al. Experiences of biliary interventions using short double-balloon enteroscopy in patients with Rouxen-Y anastomosis or hepaticojejunostomy. Dig Endosc 2010; 22: 211216 
[24] Sato T, Kogure H, Nakai Y et al. Double-balloon endoscopy-assisted treatment of hepaticojejunostomy anastomotic strictures and predictive factors for treatment success. Surg Endosc 2020; 34: 16121620

[25] Hakuta R, Kawahata S, Kogure $\mathrm{H}$ et al. Endoscopic papillary large balloon dilation and endoscopic papillary balloon dilation both without sphincterotomy for removal of large bile duct stones: A propensitymatched analysis. Dig Endosc 2019; 31: 59-68

[26] Hakuta R, Hamada T, Nakai Y et al. Multicenter retrospective and comparative study of 5-minute versus 15-second endoscopic papillary balloon dilation for removal of bile duct stones. Endosc Int Open 2017; 5: E1027-E1034

[27] Itoi T, Ryozawa S, Katanuma A et al. Japan Gastroenterological Endoscopy Society guidelines for endoscopic papillary large balloon dilation. Dig Endosc 2018; 30: 293-309

[28] Ozawa N, Yasuda I, Doi S et al. Prospective randomized study of endoscopic biliary stone extraction using either a basket or a balloon catheter: the BasketBall study. J Gastroenterol 2017; 52: 623-630

[29] Kogure $\mathrm{H}$, Yamada A, Isayama $\mathrm{H}$ et al. Multiple metal stenting using a double-balloon endoscope for malignant biliary obstruction in a patient with hepaticojejunostomy. Endoscopy 2014; 46 UCTN: E472473

[30] Cotton PB, Eisen GM, Aabakken L et al. A lexicon for endoscopic adverse events: report of an ASGE workshop. Gastrointest Endosc 2010; 71: 446-454

[31] Kanda Y. Investigation of the freely available easy-to-use software 'EZR' for medical statistics. Bone Marrow Transplant 2013; 48: 452458

[32] Wang AY, Sauer BG, Behm BW et al. Single-balloon enteroscopy effectively enables diagnostic and therapeutic retrograde cholangiography in patients with surgically altered anatomy. Gastrointest Endosc 2010; 71: 641-649
[33] Shah R, Smolkin M, Yen R et al. A multicenter, U.S. experience of single-balloon, double-balloon, and rotational overtube-assisted enteroscopy ERCP in patients with surgically altered pancreaticobiliary anatomy (with video). Gastrointest Endosc 2013; 77: 593-600

[34] Cabre M, Serra-Prat M, Palomera E et al. Prevalence and prognostic implications of dysphagia in elderly patients with pneumonia. Age Ageing 2010; 39: 39-45

[35] Wirth R, Dziewas R, Beck AM et al. Oropharyngeal dysphagia in older persons - from pathophysiology to adequate intervention: a review and summary of an international expert meeting. Clin Interv Aging 2016; 11: 189-208

[36] Katsinelos P, Kountouras ], Chatzimavroudis G et al. Outpatient therapeutic endoscopic retrograde cholangiopancreatography is safe in patients aged 80 years and older. Endoscopy 2011; 43: 128-133

[37] Raithel M, Dormann H, Naegel A et al. Double-balloon-enteroscopybased endoscopic retrograde cholangiopancreatography in post-surgical patients. World J Gastroenterol 2011; 17: 2302-2314

[38] Tanisaka Y, Ryozawa S, Mizuide M et al. Analysis of the factors involved in procedural failure: Endoscopic retrograde cholangiopancreatography using a short-type single-balloon enteroscope for patients with surgically altered gastrointestinal anatomy. Dig Endosc 2019; 31: 682-689

[39] De Koning M, Moreels TG. Comparison of double-balloon and singleballoon enteroscope for therapeutic endoscopic retrograde cholangiography after Roux-en-Y small bowel surgery. BMC Gastroenterol 2016; 16: 98

[40] Yane K, Katanuma A, Maguchi H et al. Short-type single-balloon enteroscope-assisted ERCP in postsurgical altered anatomy: potential factors affecting procedural failure. Endoscopy 2017; 49: 69-74

[41] Park TY, Song T]. Recent advances in endoscopic retrograde cholangiopancreatography in Billroth II gastrectomy patients: A systematic review. World J Gastroenterol 2019; 25: 3091-3107 
- Supplementary Table 1 Univariable and multi-variable logistic regression analyses to assess the association of age with incidence of early adverse events associated with balloon endoscope-assisted endoscopic retrograde cholangiopancreatography.

\begin{tabular}{|c|c|c|c|c|c|c|}
\hline \multirow[b]{2}{*}{ Subgroup } & \multirow[b]{2}{*}{ Total $\mathbf{n}$} & \multirow[b]{2}{*}{ eAE, n (\%) } & \multicolumn{4}{|l|}{ OR $(95 \% \mathrm{Cl})$} \\
\hline & & & Univariable & $P$ value & Multivariable $^{1}$ & $P$ value \\
\hline \multicolumn{7}{|l|}{ Age } \\
\hline - <75 years & 357 & $32(9.0 \%)$ & 1 (referent) & & 1 (referent) & \\
\hline - $\geq 75$ years & 211 & $25(12 \%)$ & $1.37(0.79-2.37)$ & 0.27 & $1.36(0.74-2.51)$ & 0.32 \\
\hline \multicolumn{7}{|l|}{ Gender } \\
\hline - Female & 208 & $20(9.6 \%)$ & 1 (referent) & & & \\
\hline - Male & 360 & $37(10 \%)$ & $1.08(0.61-1.91)$ & 0.80 & & \\
\hline \multicolumn{7}{|l|}{ Performance Status } \\
\hline . $<2$ & 497 & $50(10 \%)$ & 1 (referent) & & & \\
\hline - $\geq 2$ & 71 & $7(9.9 \%)$ & $0.98(0.43-2.25)$ & 0.96 & & \\
\hline \multicolumn{7}{|l|}{ ASA-PS } \\
\hline - $\leq 2$ & 433 & $48(11 \%)$ & 1 (referent) & & & \\
\hline .2 & 135 & $9(6.7 \%)$ & $0.57(0.27-1.20)$ & 0.14 & & \\
\hline \multicolumn{7}{|l|}{ Indication for ERCP } \\
\hline - BBS & 158 & $17(11 \%)$ & 1 (referent) & & 1 (referent) & \\
\hline - Bile duct stone & 236 & $29(12 \%)$ & $1.16(0.62-2.19)$ & 0.73 & $0.97(0.40-2.36)$ & 0.94 \\
\hline - $\mathrm{MBO}$ & 89 & $4(4.5 \%)$ & $0.39(0.13-1.20)$ & 0.10 & $0.70(0.20-2.49)$ & 0.58 \\
\hline - Cholangitis & 45 & $2(4.4 \%)$ & $0.39(0.09-1.74)$ & 0.22 & $1.56(0.30-8.15)$ & 0.60 \\
\hline - Pancreatic intervention & 40 & $5(13 \%)$ & $1.18(0.41-3.43)$ & 0.76 & $6.47(1.67-25.2)$ & 0.007 \\
\hline \multicolumn{7}{|l|}{ Type of surgery } \\
\hline - Extrahepatic bile duct resection & 110 & $10(9.1 \%)$ & 1 (referent) & & & \\
\hline - Gastrectomy & 217 & $26(12 \%)$ & $1.36(0.63-2.94)$ & 0.43 & & \\
\hline - PD & 183 & $16(8.7 \%)$ & $0.96(0.42-2.19)$ & 0.92 & & \\
\hline - Other & 58 & $5(8.6 \%)$ & $0.94(0.31-2.90)$ & 0.92 & & \\
\hline \multicolumn{7}{|l|}{ Gastrointestinal reconstruction } \\
\hline - Billroth-II & 141 & $13(9.2 \%)$ & 1 (referent) & & & \\
\hline - Roux-en-Y & 409 & $42(10 \%)$ & $1.13(0.59-2.17)$ & 0.72 & & \\
\hline - Other & 18 & $2(11 \%)$ & $1.23(0.25-5.96)$ & 0.80 & & \\
\hline \multicolumn{7}{|l|}{ Antithrombotic agents } \\
\hline - No & 4514 & $53(10 \%)$ & 1 (referent) & & & \\
\hline - Yes & 54 & $4(7.4 \%)$ & $0.70(0.24-2.00)$ & 0.50 & & \\
\hline \multicolumn{7}{|l|}{ Type of scope } \\
\hline - El-580BT & 316 & $30(9.5 \%)$ & 1 (referent) & & & \\
\hline - EC-450BI5 or EI-530B & 252 & $27(11 \%)$ & $1.14(0.66-1.98)$ & 0.63 & & \\
\hline \multicolumn{7}{|l|}{ Successful scope insertion } \\
\hline - No & 53 & $1(1.9 \%)$ & 1 (referent) & & 1 (referent) & \\
\hline - Yes & 515 & $56(11 \%)$ & $6.34(0.86-46.8)$ & 0.07 & $1.41(0.17-11.5)$ & 0.76 \\
\hline
\end{tabular}


- Supplementary Table $1 \quad$ (Continuation)

\begin{tabular}{|c|c|c|c|c|c|c|}
\hline \multirow[b]{2}{*}{ Subgroup } & \multirow[b]{2}{*}{ Total $\mathbf{n}$} & \multirow[b]{2}{*}{ eAE, n (\%) } & \multicolumn{4}{|l|}{ OR $(95 \% \mathrm{Cl})$} \\
\hline & & & Univariable & $P$ value & Multivariable $^{1}$ & $P$ value \\
\hline \multicolumn{7}{|c|}{ Bile duct stone removal } \\
\hline - No & 315 & $17(5.4 \%)$ & 1 (referent) & & 1 (referent) & \\
\hline - Yes & 253 & $40(16 \%)$ & $3.29(1.82-5.96)$ & $<0.001$ & $4.37(1.74-11.0)$ & 0.002 \\
\hline \multicolumn{7}{|l|}{ Sphincteroplasty } \\
\hline - No & 442 & $38(8.6 \%)$ & 1 (referent) & & 1 (referent) & \\
\hline - EPBD & 79 & $8(10 \%)$ & $1.20(0.54-2.67)$ & 0.66 & $0.59(0.21-1.61)$ & 0.30 \\
\hline - EPLBD & 47 & $11(23 \%)$ & $3.25(1.53-6.90)$ & 0.002 & $1.47(0.55-3.91)$ & 0.45 \\
\hline \multicolumn{7}{|c|}{ Balloon dilation for biliary or pancreatic stricture } \\
\hline - No & 3 & $38(11 \%)$ & 1 (referent) & & & \\
\hline - Yes & 139 & $18(13 \%)$ & $1.26(0.70-2.30)$ & 0.44 & & \\
\hline \multicolumn{7}{|c|}{ Biliary stent placement } \\
\hline - No & 373 & $27(7.2 \%)$ & 1 (referent) & & 1 (referent) & \\
\hline - Yes & 195 & $30(15 \%)$ & $2.33(1.34-4.05)$ & 0.003 & $3.22(1.65-6.26)$ & $<0.001$ \\
\hline \multicolumn{7}{|l|}{ Procedure time } \\
\hline " $\leq 90$ minutes & 411 & $31(7.5 \%)$ & (referent) & & (referent) & \\
\hline - $>90$ minutes & 157 & $26(17 \%)$ & $2.43(1.39-4.25)$ & 0.002 & $1.98(1.08-3.60)$ & 0.03 \\
\hline
\end{tabular}

ASA-PS, American Society of Anesthesiologists Physical Status Classification; BBS, benign biliary stricture; CI, confidence interval; eAE, early adverse event; EPBD, endoscopic papillary balloon dilation; EPLBD, endoscopic papillary large balloon dilation; ERCP, endoscopic retrograde cholangiopancreatography; GI, gastrointestinal; $\mathrm{MBO}$, malignant biliary obstruction; OR, odds ratio; PD pancreaticoduodenectomy.

1 In addition to age, variables with $\mathrm{P}<0.10$ in univariable analyses were entered into the multivariable model.

- Supplementary Table 2 Incidences and severities of early adverse events associated with balloon endoscope-assisted endoscopic retrograde cholangiopancreatography in all procedure sessions during the study period.

\begin{tabular}{|c|c|c|c|}
\hline Early adverse events ${ }^{1}$ & Elderly $(n=465)$ & Non-elderly $(\mathrm{n}=\mathbf{8 9 8})$ & $P$ value \\
\hline Total & $44(9.5 \%)$ & $65(7.2 \%)$ & 0.17 \\
\hline GI perforation $†$ & $11(2.4 \%)$ & $14(1.6 \%)$ & 0.29 \\
\hline - Severe & $5(1.1 \%)$ & $1(0.1 \%)$ & 0.02 \\
\hline Aspiration pneumonia & $10(2.2 \%)$ & $2(0.2 \%)$ & $<0.001$ \\
\hline - Severe & 0 & 0 & NA \\
\hline Pancreatitis & $7(1.5 \%)$ & $19(2.1 \%)$ & 0.53 \\
\hline - Severe & $2(0.4 \%)$ & 0 & 0.12 \\
\hline Bleeding & $2(0.4 \%)$ & $4(0.4 \%)$ & 0.99 \\
\hline - Severe & 0 & $1(0.1 \%)$ & 0.99 \\
\hline Cholangitis & $11(2.4 \%)$ & $25(2.8 \%)$ & 0.72 \\
\hline Cholecystitis & $3(0.6 \%)$ & 0 & 0.04 \\
\hline Other & $4(0.9 \%)$ & $2(0.2 \%)$ & 0.19 \\
\hline
\end{tabular}

